\title{
Editorial: Novel Approaches to Teaching Scientific Thinking: Psychological Perspectives
}

\author{
Rodney M. Schmaltz ${ }^{1 *}$ and Scott O. Lilienfeld ${ }^{2,3}$ \\ ${ }^{1}$ Department of Psychology, MacEwan University, Edmonton, AB, Canada, ${ }^{2}$ Department of Psychology, Emory University, \\ Atlanta, GA, United States, ${ }^{3}$ School of Psychological Sciences, University of Melbourne, Melbourne, Australia
}

Keywords: scientific thinking, misconceptions, cognitive biases, science teaching, creationism, dualism, signal detection, heavy metal music

\section{Editorial on the Research Topic}

\section{Novel Approaches to Teaching Scientific Thinking: Psychological Perspectives}

Traditionally, the educational field has adhered to a "knowledge deficit" model of science learning in which the principal problem confronting students is a dearth of accurate knowledge (Bak, 2001). Nevertheless, filling up pupils' minds with facts and figures, although necessary, is rarely sufficient as an educational goal. Even with an adequate knowledge base, many students are incapable of evaluating assertions with a discerning and appropriately critical eye. Along with this recognition is an awareness that science is more than a body of knowledge; it is an epistemic approach to evidence (Sagan, 1995) that emphasizes error-reduction.

Indeed, scholars have espoused the need to promote scientific thinking for many years, even decades (e.g., Mackay, 1869; Gardner, 1957; Randi, 1982; Shermer, 2011). Often, historical treatises on the requirement for scientific skepticism begin with the notion that now, more than ever, we need to teach our students how think scientifically about claims in everyday life. Although it sounds cliched to say it again, the need to promote scientific thinking skills may indeed be needed now more than ever. The growing deemphasis on the importance of factual information, as well as the understandable difficulty many students encounter in distinguishing print, online, and media information from misinformation renders this Research Topic particularly timely.

Scientific thinking - the ability to generate, test, and evaluate claims in ways that minimize our inherent propensities toward bias (e.g., Koerber et al., 2015) -is crucially important for our students, who are continually exposed to nearly limitless information and misinformation online. In today's world, even legitimate news organizations at times promote invalid and misleading information. It can be exceedingly challenging for students, and even their instructors, to distinguish wheat from chaff and to accurately determine the validity of claims. This Research Topic in Frontiers in Educational Psychology focuses on strategies to help instructors promote sound scientific thinking. Even after extensive training in science at a postsecondary level, many pseudoscientific beliefs may persist (e.g., Winer et al., 2002). Hence, we may need to explore novel approaches to dispelling such beliefs in students. The articles presented here provide a wide range of approaches to promoting scientific thinking, and cover a range of topics from the misuse of psychological terms to user-friendly demonstrations in neuroscience.

A lack of understanding of the nature of science bears significant real world implications. For example, $40 \%$ of Americans do not believe there is a scientific consensus on climate change (National Science Board, Science and Engineering Indicators, $2016^{1}$ ), and the American president

${ }^{1}$ National Science Board, Science and Engineering Indicators (2016). Arlington, VA: National Science Foundation (NSB2016-1) 
(as of the time of this writing), has endorsed such unsupported notions such as the debunked assertion that vaccines cause harm, or that global warning trends are a "hoax" (2016; Berezow and Campbell, 2017). In fairness to him, the embrace of dubious scientific claims, including those in psychology and allied fields, is clearly bipartisan (Duarte et al., 2015).

The papers in this issue adopt a broad and diverse approach to teaching scientific thinking. Lilienfeld et al. discuss 50 psychological and psychiatric terms that are inaccurate, commonly misused, or both. They discuss why these terms are often used incorrectly, and provide students and instructors alike with strategies to correct misconceptions of the terms, along with recommendations for preferable terms.

Matute et al. demonstrate the role of the illusion of causality in fostering continued belief in pseudoscience and misinformation. An overview of the innovative experiments in the Matate lab show that an understanding of the illusion of causality can promote of scientific thinking.

Hamilton and Hamilton explore how illusions that demonstrate key concepts in neuroscience can be profitably applied to philosophical arguments. In this regard, the authors place a particular emphasis on mind-body dualism, which is a deeply entrenched assumption among many beginning students.

The promotion of scientific thinking may be a valuable window into the discussion of controversial topics. For example, Honey describes the value of bringing supernatural views into the classroom. Specifically, she argues that if students are not exposed to the logical flaws of pseudoscientific or otherwise nonscientific views, they may continue to see supernatural perspectives, such as creationism, as viable alternatives to science. Schmaltz similarly proposes that controversial examples found in popular culture,

\section{REFERENCES}

(2016). Areas to watch in 2017. Science 354:1524. doi: $10.1126 /$ science.354.631 9.1524

Bak, H. J. (2001). Education and public attitudes toward science: implications for the "deficit model" of education and support for science and technology. Soc. Sci. Q. 82, 779-795. doi: 10.1111/0038-4941.00059

Berezow, A., and Campbell, H. (2017). Ignore Anti-Vaccine Hysteria, Mr. Trump. Wall Street Journal - Online Edition. Available online at: https://www.wsj.com/ articles/ignore-anti-vaccine-hysteria-mr-trump- 1484093196

Duarte, J. L., Crawford, J. T., Stern, C., Haidt, J., Jussim, L., and Tetlock, P. E. (2015). Political diversity will improve social psychological science. Behav. Brain Sci. 38, 1-13. doi: 10.1017/S0140525X14000430

Gardner, M. (1957). Fads and Fallacies in the Name of Science. New York, NY: Dover.

Koerber, S., Mayer, D., Osterhaus, C., Schwippert, K., and Sodian, B. (2015). The development of scientific thinking in elementary school: a comprehensive inventory. Child Dev. 86, 327-336. doi: 10.1111/cdev.12298

Lilienfeld, S. O., Ammirati, R., and David, M. (2012). Distinguishing science from pseudoscience in school psychology: science and scientific thinking as safeguards against human error. J. School Psychol. 50, 7-36. doi: 10.1016/j.jsp.2011.09.006

Mackay, C. (1869). Memoirs of Extraordinary Popular Delusions and the Madness of Crowds. London: George Routledge and Sons. such as the harm supposedly caused by listening to heavy metal music, can provide engaging examples to help students think like scientists.

Anderson discusses how pseudoscientific examples can be used to help students understand the value of signal detection theory. By incorporating engaging examples of pareidolia and psychic detectives, Anderson demonstrates how signal detection theory can frame how people make decisions regarding the accuracy of a claim.

For students, and the public at large, the ability to think like a scientist helps inform important decisions ranging from global issues, such as anthropogenic climate change, to personal issues, such as health choices (e.g., vaccine safety and dubious alternative medicine claims). This Research Topic offers readers with a wide range of valuable approaches to promoting scientific thinking. Ensuring that students are equipped with sound scientific thinking skills is no easy task, as people tend to trust their intuitions and are largely unaware of the biases that influence their decision making (Pronin et al., 2002; Lilienfeld et al., 2012). The approaches discussed in this Research Topic provide educators with a sampling of the tools necessary to safeguard students against the seductive appeal of pseudoscientific claims. With these tools, students should hopefully be better prepared to successfully sift through the reams of information-and misinformation-with which they are bombarded on a daily basis.

\section{AUTHOR CONTRIBUTIONS}

SL is the lead author on this manuscript. Both authors have contributed to the writing of this editorial.

Pronin, E., Lin, D. Y., and Ross, L. (2002). The bias blind spot: Perceptions of bias in self-versus others. Personal. Soc. Psychol. Bull. 28, 369-381. doi: 10.1177/0146167202286008

Randi, J. (1982). Flim-Flam. Buffalo, NY: Prometheus.

Sagan, C. (1995). The Demon-Haunted World: Science as a Candle in the Dark. New York, NY: Random House.

Shermer, M. (2011). The Believing Brain: From Ghosts and Gods to Politics and Conspiracies-How We Construct Beliefs and Reinforce them as Truths. New York, NY: Henry Holt.

Winer, G. A., Cottrell, J. E., Gregg, V., Fournier, J. S., and Bica, L. A. (2002). Fundamentally misunderstanding visual perception: adults' belief in visual emissions. Am. Psychol. 57:417. doi: 10.1037/0003-066X.57. 6-7.417

Conflict of Interest Statement: The authors declare that the research was conducted in the absence of any commercial or financial relationships that could be construed as a potential conflict of interest.

Copyright (C) 2017 Schmaltz and Lilienfeld. This is an open-access article distributed under the terms of the Creative Commons Attribution License (CC BY). The use, distribution or reproduction in other forums is permitted, provided the original author(s) or licensor are credited and that the original publication in this journal is cited, in accordance with accepted academic practice. No use, distribution or reproduction is permitted which does not comply with these terms. 